\title{
Vibration analyses for the local and global evaluation of bridges as a tool for structural retrofit
}

\author{
Análisis de vibraciones en la evaluación global y local de puentes como instrumento para su \\ reforzamiento estructural
}

Fabián A. Consuegra (Main and Contact Author)

Associate Engineer, Ingetec S.A.

Cra 6 No. 30A-30, Bogotá, D.C., Colombia

fabianconsuegra@ingetec.com.co

Camilo Santos

Associate Engineer, Ingetec S.A.

csantos@ingetec.com.co

\section{Resumen}

Una extensa red de puentes de gran antigüedad es parte esencial del desarrollo económico de una nación, por lo que se requiere de una minuciosa evaluación estructural para establecer su reforzamiento o recomendar su reemplazo a causa de la inviabilidad de dicho reforzamiento. Entre las dificultades que debe enfrentar el Ingeniero Estructural a cargo de dicha decisión, está la limitada información disponible que obliga a la implementación de ensayos destructivos de inspección con alta demanda de tiempo y recursos técnicos y humanos. Se propone un análisis basado en monitoreo dinámico no destructivo de los puentes de fácil implementación para conocer la condición estructural a un nivel global y local. Este trabajo muestra que el monitoreo basado en un modelo no-lineal tiene el potencial de detectar daño en estructuras más allá del alcance del modelo lineal comúnmente usado en la literatura presente. Este trabajo presenta un resumen de estudios de vibraciones en diversos puentes así como particularidades que debe conocer el ingeniero estructural para una adecuada interpretación de los resultados.

Palabras clave: Monitoreo dinámico; acelerómetros; vibraciones en puentes; calibración de modelos matemáticos; vibración no-lineal elástica.

\section{INTRODUCTION, LITERATURE REVIEW AND THE PROPOSED METHOD}

A comparison between vibration records collected through nondestructive, simple, and an accurate method and a mathematic model built for the same structure has been used to determine the structural condition of several bridges. Vibration records of bridges were obtained by means of a high-resolution acquisition system combined with a network of sensitive accelerometers.

Data was collected during time windows of 1 minute. In the first approach the main vibration frequencies of the structures were identified by the largest peaks in a Fourier Spectrum (Allemang, 2002) based on an elastic model assumption (Oppenheim, et. al., 2005).

A more refined investigation of behavior of the real structure was performed through an assumption of non-linear elastic model.

\author{
Manuscript Code: 547 \\ Date of Reception/Aceptance: 01.oct.2014/01.mar.2015
}

Abstract

A large infrastructure system of bridges is essential to economical development of a country. Given such importance, a detailed structural inspection and evaluation is required in order to decide whether the bridges may be reinforced or retrofitted to extend their service life or whether they should be replaced by new structures. The structural engineer in charge of such decisions must face the limited amount of information of old structures which leads to implementation of time-expensive destructive methods in order to obtain basic information about the structure. A dynamic monitoring combined with a non-linear modeling is proposed to enable structural identification and damage detection, beyond the scope of traditional linearmodel methods commonly used and available in the literature. This work presents several case studies on vibration records used in bridges and also specific topics that the structural engineer need to know for a good interpretation of results.

Keywords: Dynamic monitoring; accelerometers; vibrations in bridges; torsional effects in bridges; mathematical model calibration; non-linear elastic vibrations.

Natural frequency is the most common parameter used to investigate structural condition through dynamic observations (Doebling, 1996, Doebling et. al. 1998 and Sohn et. al 2003). The common approach consists of tracking changes on the natural frequency associated to drop on stiffness when the structure changes from one to another structural condition.

Instead of the classical approach of assuming the structure to behave linearly for a given condition, this work presents an alternative method to investigate structural condition based on a non-linear elastic mathematic representation of the structure.

The simplest way to calibrate a mathematic model consists of a tuning process of its dynamic properties to match the observations made on the data recorded. The natural frequency of a SDOF system with stiffness $k$ and mass $m$ is defined by (Clough and Penzien, 1975), Eq1.

Given constant mass changes in the natural frequency are associated to changes in the stiffness of the system. In the case of reinforced concrete structures such variation depends on the 
cracking level that causes sections migrate from gross to cracked inertia properties. The amount of reduction in the moment of inertia of a concrete section caused by cracking process will depend on the provided reinforcement (Ferguson et. al., 1988).

A standard practice in structural engineering is the use of a three-dimensional finite element model to calculate the natural frequencies of a system instead of the simple version of equation 1. Although such procedure can lead to more precise results, judgment of engineer continue to play the most important role when defining geometry properties, boundary conditions, elasticity of the system, dead loads, etc.

Modulus of elasticity of concrete estimated with equation 2 (Código Colombiano de Diseño Sísmico de Puentes, 1994) is the parameter with highest uncertainty due to the ample scatter of concrete strength observed for a given structure. International standards have similar expressions to equation 2 for calculation of modulus of elasticity (AASHTO 2013).

$$
f=\frac{1}{2 \pi} \sqrt{\frac{k}{m}}
$$

$E=12500 \sqrt{f^{\prime} c} \quad[\mathrm{~kg}-\mathrm{f} / \mathrm{cm} 2]$

$$
f=\frac{\pi}{2 L^{2}} \sqrt{\frac{E I}{\rho A}}
$$

Calibration of the structural model may serve as an instrument to estimate concrete strength of the bridge through equation 2 , if other parameters mentioned can be assumed or estimated with enough reliability. Unlike standard methods to measure concrete strength based on samples (cylinders or cores) taken from specific points of the structure (ASTM, 2004), results obtained with the model calibration correspond to a global estimate of the elasticity of the bridge.

\section{Comparison between a SDOF model and a $3 \mathrm{~d}$ model}

Figure 1 shows a three-dimensional model built in Sap2000 (a) and the composite section used to formulate a SDOF model (b), both used to calculate natural frequencies of the bridges considered. The 3D model consists of frame elements for the beams and shell elements for the slab, with constraints imposed on common nodes to beams and slabs in order to guarantee the full composite action.

The 3D model can represent accurately any particular feature of the bridge such non-homogeneous spacing between beams and also consider flexure and shear deformations. The SDOF model formulated in equation 3 accounts only for flexure deformations, where L, E, ? ?, A and I are length of bridge, modulus of elasticity, density of material, cross-section area and section moment of inertia, respectively. The effective width of the slab portion ("bef" in Figure 1 b) was used to define the composite section (Código Colombiano de Puentes, 1994).

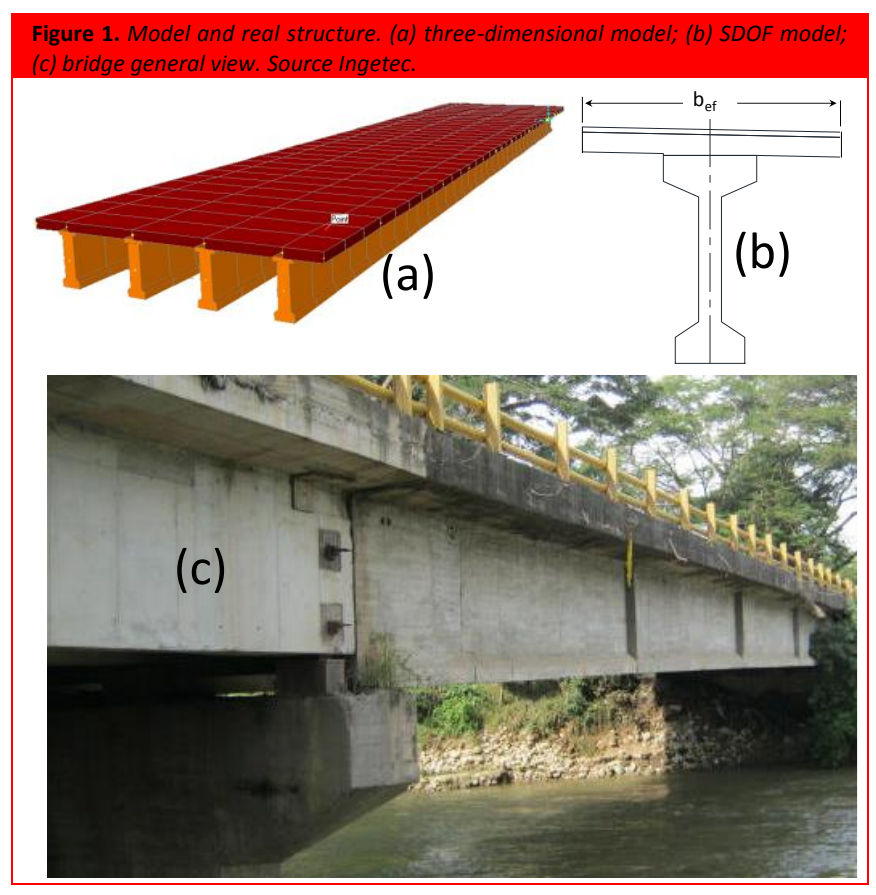

The bridge shown in Figure 1 (c) has a span length of $34 \mathrm{~m}$, four I-beams, slab thickness of $20 \mathrm{~cm}$, weathering surface of $5 \mathrm{~cm}$ and steel parapet on top of concrete barriers, and it behavior was simulated through both $3 \mathrm{D}$ and SDOF models. Natural frequencies obtained those models differed in about $1 \%$ proving that the SDOF model is enough accurate for bridges with regular geometry and homogeneous beam distribution. The largest difference found for the rest of bridges considered in this study was $10 \%$. Gross sections were used in all models.

\section{IDENTIFICATION OF FUNDAMENTAL FREQUENCY}

Figure 2 shows squared boxes for location of accelerometers on a 40m-span bridge. Three accelerometers were installed at quarter points over an exterior beam side to collect data while traffic was maintained on the bridge; the same procedure was repeated with the instrumentation located on the opposite side of the bridge. Data was recorded at 2,000sps.

Figure 3 shows the acceleration recorded at mid-span point with traffic over the bridge (a), the corresponding Fourier spectrum (b) and accelerations recorded at each of the three points of Figure 2 for a short-time window (c). It can be seen that large amplitude vibrations are recorded at instant when vehicles are passing over the bridge as revealed by spike accelerations.

The largest peak in the Fourier Spectrum shows the fundamental frequency of the bridge at $6.5 \mathrm{~Hz}$ (Allemang, 2002), which compares well to a frequency of $6.2 \mathrm{~Hz}$ estimated with a mathematic model. The measured frequency can also be 
identified by the time between consecutive peaks on the filtered acceleration records in Figure 3(c). Also in Figure 3(c) can be seen that the largest magnitude of acceleration is recorded at the mid-span point $(L / 2)$ while smaller magnitudes are recorded at the other points ( $\mathrm{L} / 4$ and $3 / 4 \mathrm{~L})$, the ratios of those magnitudes resemble the mode shape associated to the identified frequency.

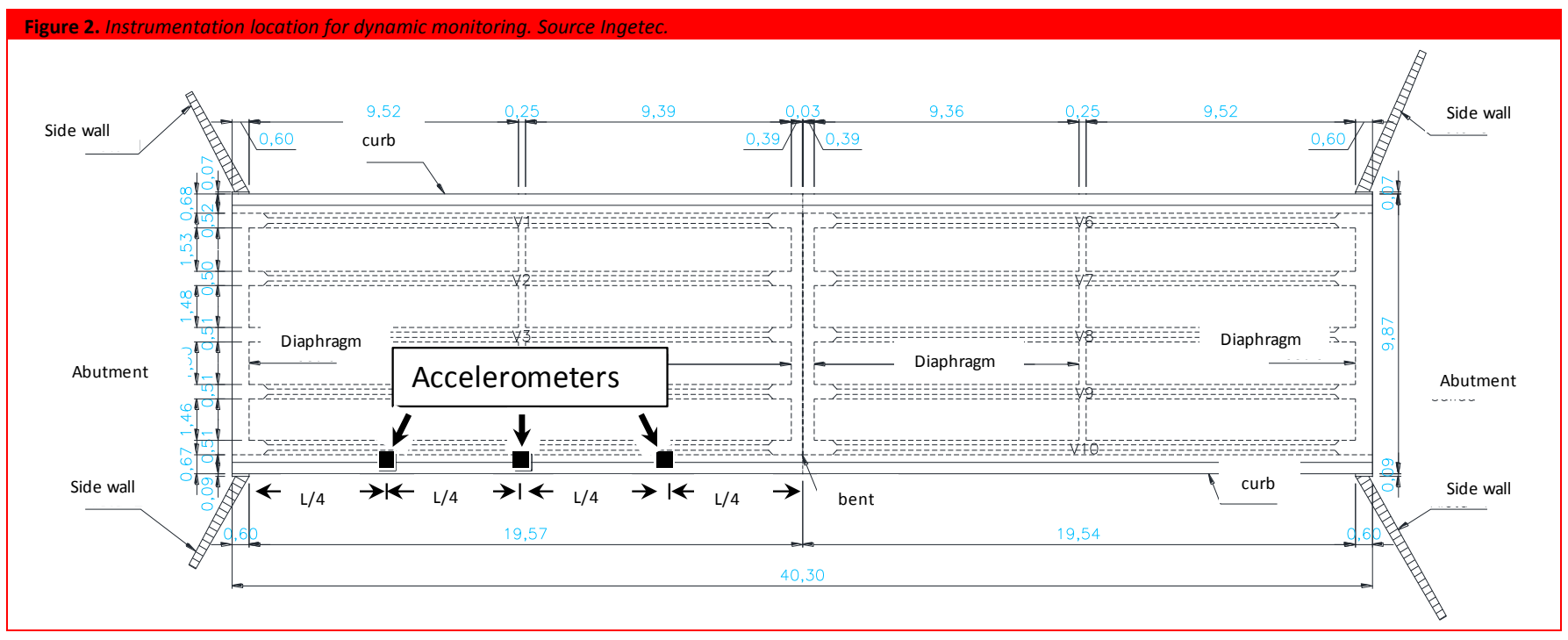

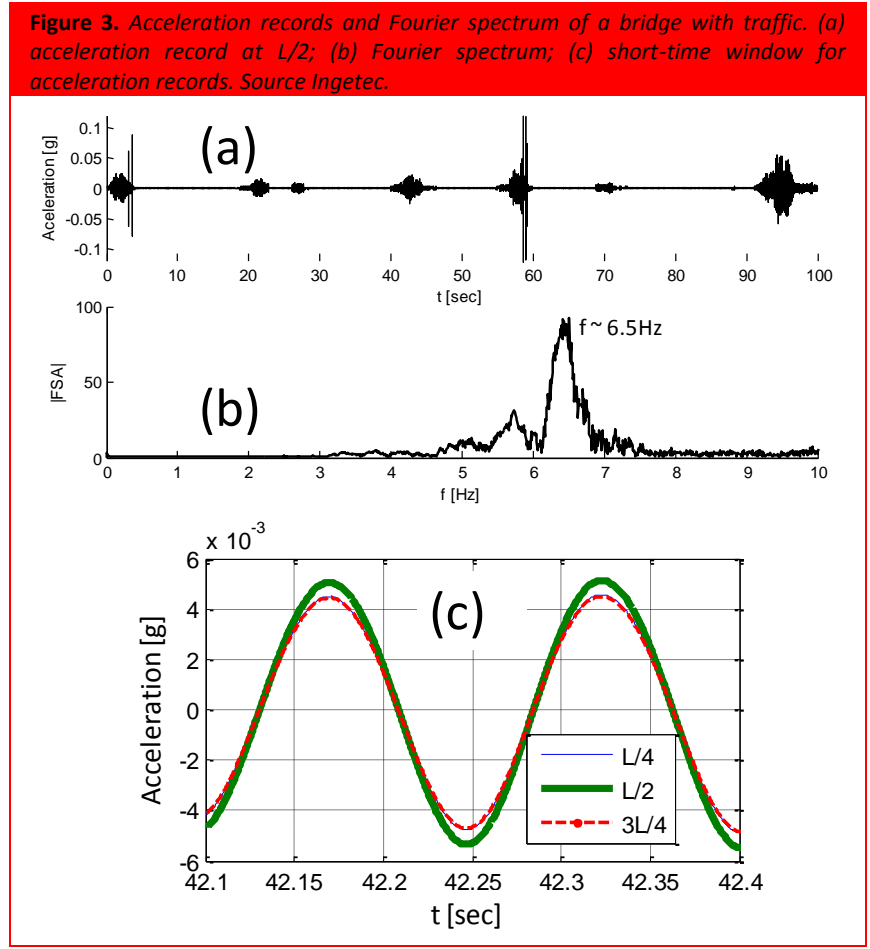

COMPARISON OF MEASURED AND CALCULATED NATURAL FREQUENCIES FOR BRIDGES TESTED model built with a modulus of elasticity obtained with equation 2 , for more than 40 bridges tested. The bridges were reinforced and post-tensioned concrete of one and two spans. The comparison indicated that a natural frequency calculated with the model would not match that indicated by the largest peak in the Fourier spectrum ("Pick Peak", Allemang 2012) if some aspects are not considered. Those aspects are accuracy in the model construction related to geometry and boundary conditions, geometric configuration of the bridge, characteristics of the passing load associated to stronger excitation for higher modes and the effect of the dynamic modulus of elasticity (Popovic et. al. 2008).

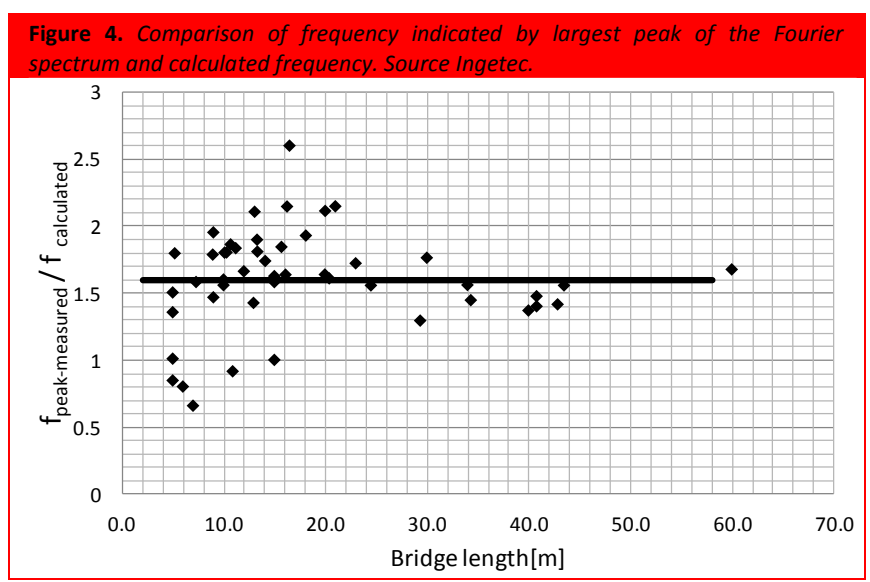

Figure 4 shows a comparison between the measured natural frequency (identified in the same manner as in Figure $3 \mathrm{~b}$ ) and the calculated frequency with a simply supported mathematic 
Dynamic response associated to the combined effect of flexure and torsion in a bridge

The SDOF model used to simulate the behavior of the bridges corresponds to a formulation to calculate the natural frequency of a simply supported beam under flexural deformations. Although analog formulations could be used to estimate higher flexural frequencies (Timoshenko, 1937), analytical calculation of torsional mode of the bridges would demand of more complex expressions seldom used. Alternatively to such procedure a 3D finite element model could be used to calculate the torsional frequencies of the bridge, despite to more time and effort needed in preparation of the model.

Typically, the instrumentation is to be located over the cantilever areas of the slab because data was to be recorded while traffic was maintained on the bridge. As a consequence of the geometric configuration of the bridges, accelerations recorded on those areas were prone to contain torsional vibrations of magnitudes as important as those for flexural vibrations.

A robust process capable of distinguishing between flexural and torsional modes was required, particularly for those bridges with geometric configurations such the main flexural and torsional natural frequencies were of similar values.Figure 5 shows the recorded acceleration at the mid-span in the time (a) and frequency domains ( $b$ and $c$ ) with the instrumentation located over the cantilever area of the slab in a similar manner to that shown in Figure 2 for another bridge case. The peaks in the Fourier spectrum of Figure $5 \mathrm{c}$ show the two main frequencies of $2.6 \mathrm{~Hz}$ and $3.4 \mathrm{~Hz}$.

The spectrogram of Figure $5 \mathrm{~b}$ shows the participation of each of the main frequencies over the same 10-second window of Figure $5 \mathrm{a}$. Based on the intensity of each frequency revealed by colors it can be seen that the frequency of $3.4 \mathrm{~Hz}$ has strong participation during initial instants of the record while the bridge vibrates mainly in the frequency of $2.6 \mathrm{~Hz}$ for the rest of the record. In contrast to Figure $3 \mathrm{~b}$ where the accelerations recorded contains only one frequency depicted by almost a unique peak in the Fourier spectrum, further investigation on the accelerations recorded for this bridge is needed in order to distinguish between flexural and torsional modes.

Figure 6 a shows the accelerometers installed on the same bridge depicted in Figure 5 with a different configuration to that shown in Figure 2. This configuration consists of locating two sensors on the same section along the bridge, one on each center beam to each side of the longitudinal axis. Accelerations for the flexural mode at location points of sensors are similar while accelerations for the torsional mode are of similar magnitudes and opposite sign, as represented by a1 and a2 in Figure 6 a.

Consequently, sum of the records $(a 1+a 2)$ as shown in Figure 6 $\mathrm{b}$ and subtraction of the records (a1-a2) as shown in Figure $6 \mathrm{~d}$, give new records with isolated contents of flexure and torsion respectively. The Fourier spectrum of the sum (Figure $6 \mathrm{c}$ ) and subtraction (Figure 6 e) of the records identify unique frequencies of $2.6 \mathrm{~Hz}$ and $3.4 \mathrm{~Hz}$ for flexure and torsion respectively. The current configuration of sensors although is very efficient in distinguishing two close-spaced modes to avoid misinterpretations as that of Figure 4, is seldom practical because of difficulties to access some locations in the bridge.
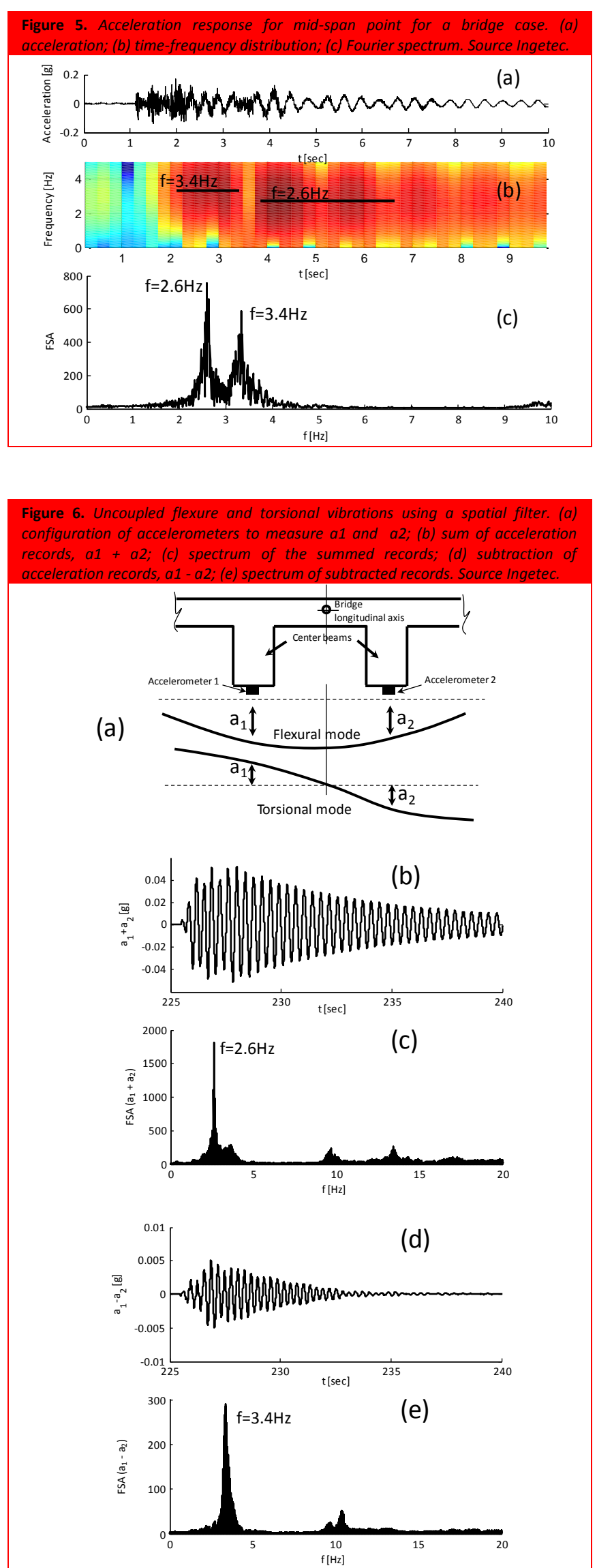


\section{REAL BOUNDARY CONDITIONS OF THE STRUCTURE}

Mathematic model results are very sensitive to boundary conditions therefore actual supporting conditions must be well represented in order to obtain reliable results. It is a common practice to assume the bridge to be a simply supported beam over bents or abutments.

However, depending on quality control of the construction or absence of neoprene supports, the bridge may actually have a partial restriction to rotation at supports which strongly affects its dynamic behavior.

Figure 7 shows a reinforced concrete bridge $24 \mathrm{~m}$ span (a) in which the superstructure beam has been casted monolithically with the concrete abutment (b). As a result of this configuration, the superstructure and the abutments become a frame system (integral abutments) that differs from the original design dictated by the simply supported beams assumption. Actual structural support conditions can be investigated by using the dynamic monitoring through the simple model shown in Figure $7 \mathrm{c}$.
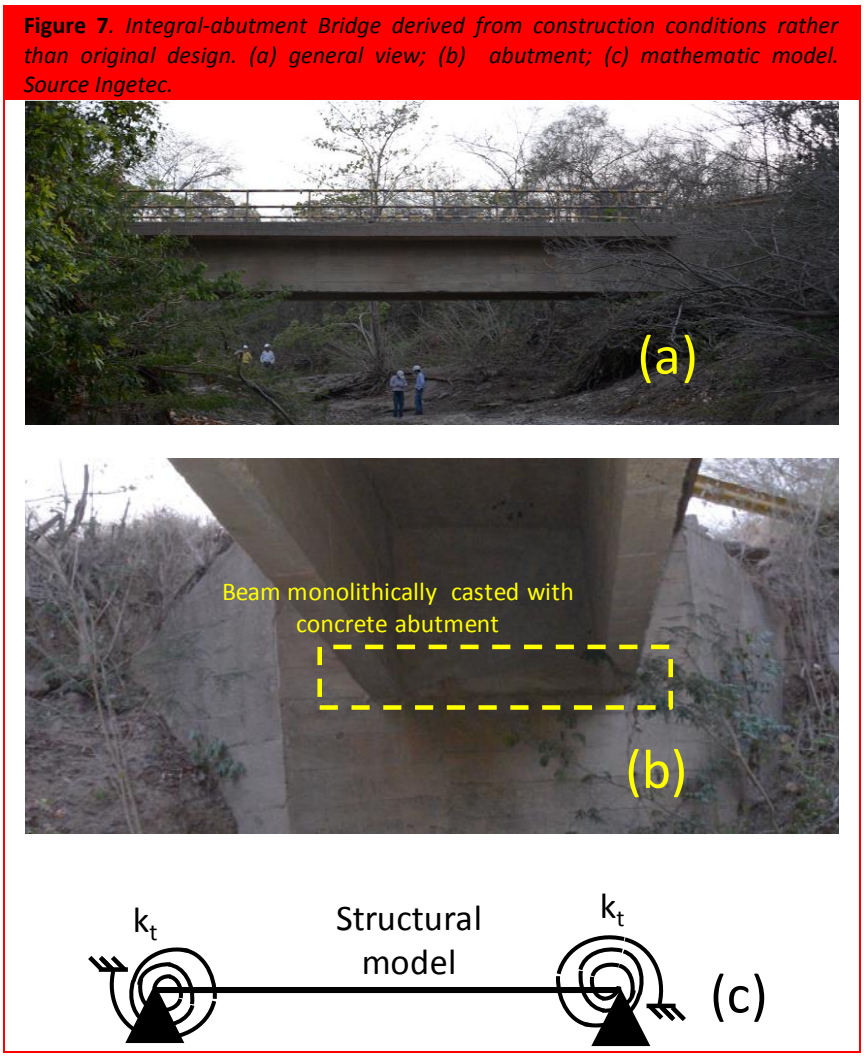

Properties of the rotational spring at the supports ( $k t$ in Figure 7 c) can be obtained through observation of the dynamic behavior of the bridge. Once the rotational springs are determine a full understanding of the bridge dynamic may be obtained.

The stiffness of the simply supported beam (384El/5qL4) is increased by a factor of 5 when the fully-restrained condition is achieved (384El/qL4), consequently the natural frequency calculated with a simply-supported beam model may be off by a factor of more than 2 (equation 1 ).

This additional stiffness due to supporting conditions of the bridge may be another important factor that causes differences between calculated and measured natural frequencies in Figure 4. An analytical expression to obtain the torsional stiffness at supports is shown in equation 4 :

$k_{t}=\frac{5 E I}{48 L} \frac{\left(1-\frac{1}{\text { factor }}\right)}{\left[\frac{1}{24}-\frac{5}{96}\left(1-\frac{1}{\text { factor }}\right)\right]}$

where "E", "I", "L" and "factor" are the modulus of elasticity, section moment of inertia, span length and ratio between stiffness measured and that calculated for the simply-supported beam bridge model, respectively.

The simply-supported beam was adjusted to incorporate the rotational springs as shown in Figure 8 a. Based on the calibrated model main modes were identified as shown in the comparison in Figure $8 \mathrm{~b}$ (flexure) and Figure $8 \mathrm{c}$ (torsion). It can be seen that the model with the torsional springs (Sap2000) better represents actual behavior of the bridge ("Partially restrained rotation").

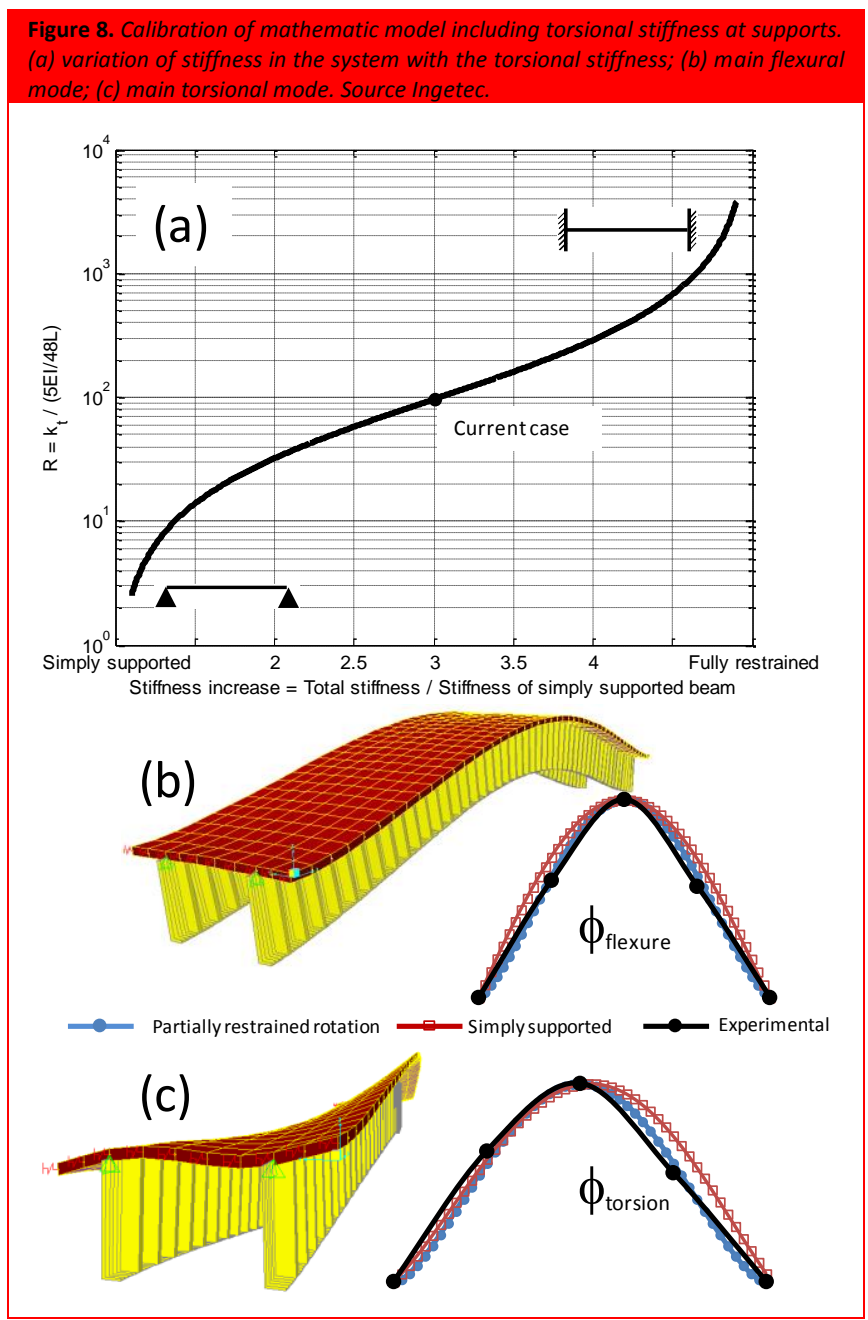




\section{Non-linearity as an instrument for damage detection}

A linear-elastic (constant stiffness) model is commonly used to investigate small-amplitude vibrations in structural engineering. However, in a more general sense a mechanical system can be represented by a displacement-dependent stiffness (Consuegra et. al., 2012). Consequently, the vibration frequency of the system observed at a given instant will be function of the displacement amplitude and the non-linear elastic stiffness model may be more accurate than the classical linear approach. By definition a linear-elastic system has constant natural frequencies and mode shapes associated to constant stiffness matrices that represent the structure.

Stiffness non-linearity of a structure can be identified by tracking variation of a specific mode shape and/or natural frequency during mechanical vibrations. Equation 5 leads to estimate of the given natural frequency " $\mathrm{i}$ " as a function of the corresponding mode shape " $\mathrm{i}$ " and stiffness and mass matrices. When natural frequency changes at a given instant the mode shape associated will change as well and vice-versa.

$$
\omega_{i}^{2}=\frac{\phi_{i}^{T}[K] \phi_{i}}{\phi_{i}^{T}[M] \phi_{i}}
$$

Figure 9 shows the vibrations recorded in a fairly linearly behaved system, thus, a bridge without stiffness non-linearity observed in the dynamic response. One sensor was installed on each side at the mid-span point (a) and vertical vibrations (b) were used to identify the main torsional mode, with the corresponding mode shape calculated by normalizing the two acceleration amplitudes with respect to each other (c). It can be seen that the torsional mode shape is represented by a ratio value of about -1.0 which indicates that accelerations recorded on each side are of similar magnitude and opposite sign as expected for an undamaged bridge.

A full standard structural evaluation was performed on the bridge by taking concrete cores and reinforcing bars samples to determine the mechanical properties of materials, also carbonation and corrosion tests were performed. The full investigation corroborated the bridge has an adequate structural condition as seen from the perspective of stiffness nonlinearity explained previously.

A bridge with large damage and high cracking level unlike that of Figure 9 is shown in Figure 10. The crack marked up in Figure 10 a crosses the entire post-tensioned beam section from top to bottom. The full investigation of the bridge according to standard methods as mentioned previously (extraction of samples and other tests), concluded the bridge had a structural capacity lower than the actual demand associated to current traffic conditions

Figure 11 shows an analysis similar of that in Figure 9 for the damaged bridge in Figure 10. The main flexural mode shown in Figure $11 \mathrm{~d}$ was obtained by normalizing accelerations a1 and a2 with respect to acceleration a3 (mid-span points). Variation in the observed mode was about $80 \%$ as the vibration amplitudes decrease (mode shape values between -0.45 and 0.09 in Figure $11 \mathrm{~d}$ ). Comparison of dynamic behavior of bridges in Figure 9 and Figure 11 shows that structural damage is associated to the stiffness nonlinearity observed.
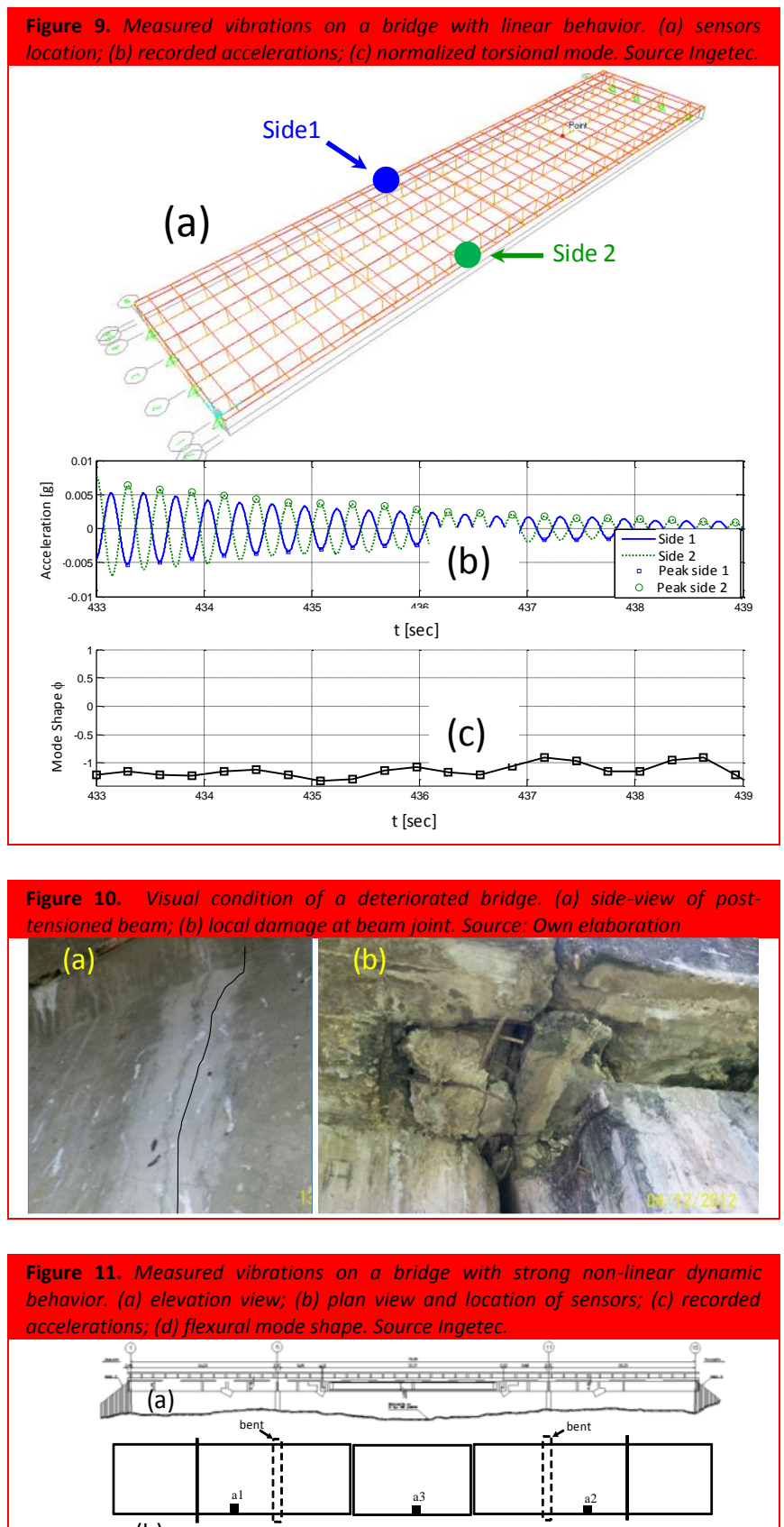

(b)

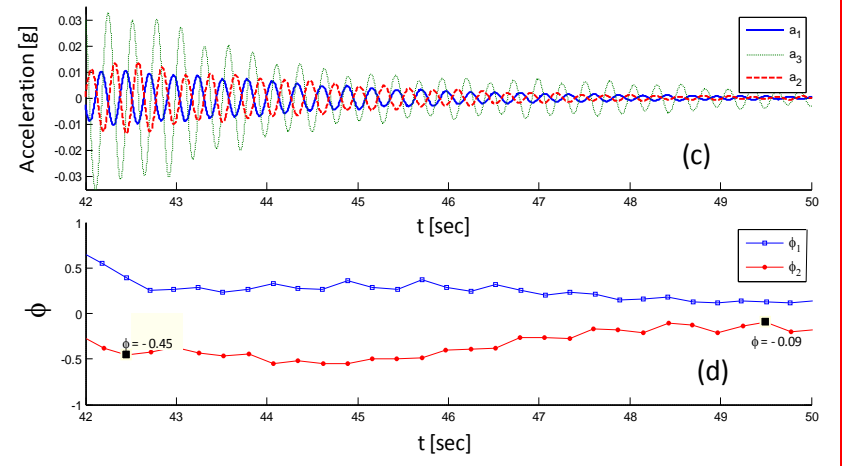


Analysis of mechanical vibrations through dynamic monitoring leads to determine structural conditions of bridges. The structural engineer in charge of the analyses must have adequate understanding of the modal identification methods, be aware of contribution of flexure and torsion in the dynamic behavior of bridges, and be capable to provide a reasonable representation of the boundary conditions of the real structure. Nonlinearity has been proved to be a promising technique to investigate structural condition that the engineer could use as a tool for making decisions on structural retrofitting.

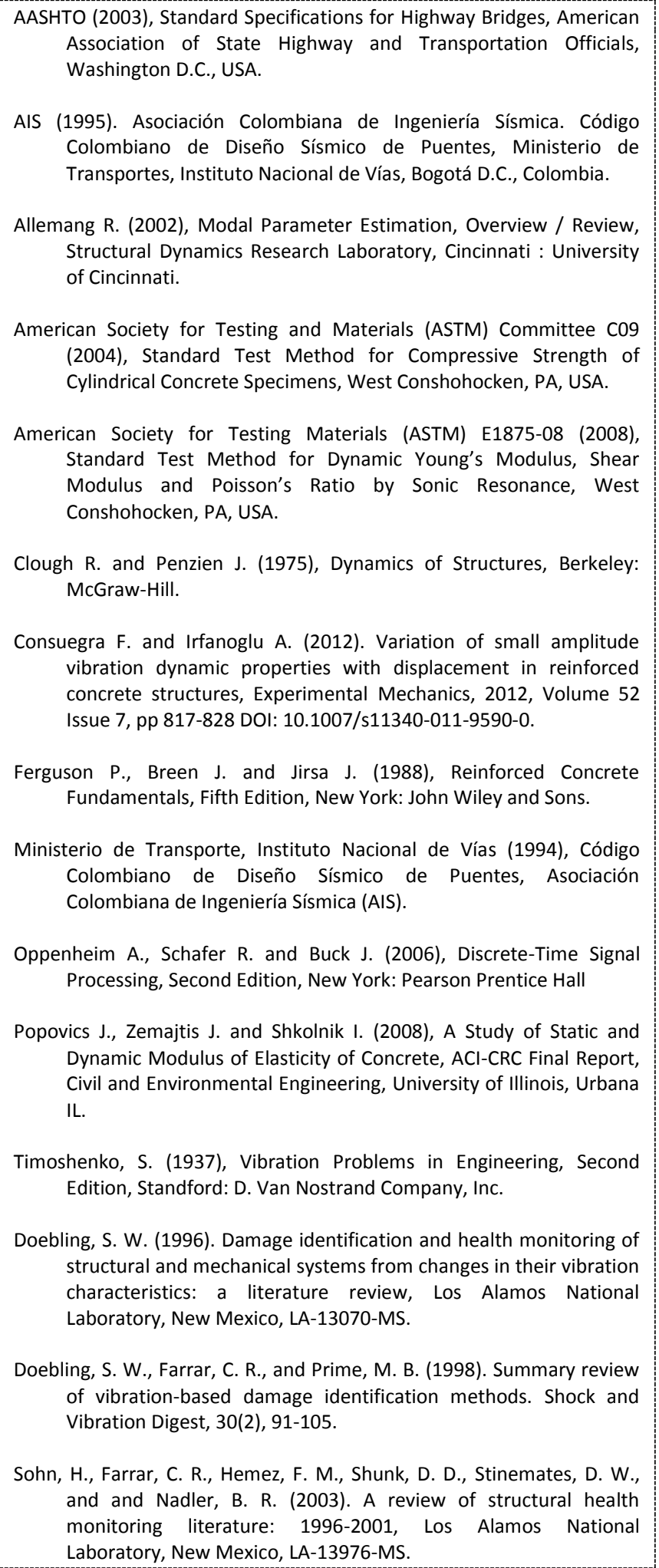

